\title{
Rotoscoping Architecture, Productive and Morphogenetic Processes
}

\author{
Rodrigo Martin Iglesias \\ Universidad de Buenos Aires, Argentina \\ rodrigo.martin@fadu.uba.ar
}

\section{Francesco Milano}

Centro Hipermediático Experimental

Latinoamericano, Argentina

mln.frncsc@gmail.com

\author{
Karen Antorveza \\ Centro Hipermediático Experimental \\ Latinoamericano, Argentina \\ karenantorveza@gmail.com
}

\begin{abstract}
This paper presents the partial advances of a research project that is developing a series of theoretical, empirical and collaborative experiences, carried out through the modality of exercises implemented as workshops and produced in collaboration with groups of students, in which we study the implicit or potential relationships between the parametric generation of the form and the digital manufacturing techniques, including their feedback, as well as their possibilities of mediation between the categories of digital representation, materials and manufacturing. In particular we will take here the experiences made around the sectioning materialization strategy.
\end{abstract}

Keywords: Rotoscopy; Morphogenesis; Sectioning; Hybridization; Digital Handcraft.

\section{Introduction}

The work presented here arises from the conjunction of the theoretical and practical experiences of the authors, in the context of the institutional collaboration between the Faculty of Architecture, Design and Urbanism of the University of Buenos Aires (FADU-UBA) and the Taller de Materiales y Construcción of the Centro Hipermediático Experimental LatinoAmericano (TaMaCo-cheLA). In this context, was created the project "Fabricación Digital, procesos productivos y morfogenéticos" (PIA TRP-06) in which we work with a team of researchers, students and volunteers.

The project researches the relationship between parametric design processes and digital manufacturing processes, paying special attention to the feedback phenomena between both processes and the phenomena of technological hybridization with traditional analogical media that comes from the conditions of variability in the characteristic resources of the Latin American context (Herrera, 2016, Frogheri, 2016, García Amen, 2016, Muñoz, 2016, Sperling, 2015a, 2015b, Schunemann, 2015, Batistello, 2015). In this paper we will take part of the project carried out during the first semester of 2017, in which we focus on producing an object of architectural scale starting from the Sectioning morphoproductive category (Iwamoto, 2009) and relating it to the rotoscoping cinematographic technique. We present here the stages, the methodologies used, the results and the discussion about them.

\section{Technical Strategies}

It is important to consider that all the semester was worked with research interns and students with different levels of training and knowledge on the subject, which forced us to work simultaneously in research and teaching. This first stage of the project began with the exploration of the Sectioning category and the cases exposed in the Iwamoto book. Especially keeping the focus in the processes of translation and feedback: "How design use digital fabrication and material techniques to calibrate between virtual model and physical artifact" (Iwamoto, 2009; p.4)

Then, other cases were investigated and the possibilities opened up from the collaborative search. From the cases studied it was considered appropriate to take the Dunescape installation carried out in the year 2000 by SHoP in the MOMA PS1 (http://www.shoparc.com/projects/dunescape-at-momaps1/), in which full scale drawings were used as templates to cut the wood at the site before manual assembly. This was also due to the availability of wood slats from a previous installation (Formosa, 2017). Then several meetings were held in which the a priori implications of sectioning on form and forms more or less adequate in relation to the process were discussed. Thanks to a grant from the FNA, Lisa Iwamoto and Craig Scott can visit us, where the opportunity was taken to show them the project. Their comments and explanations were fundamental for the evolution of our ideas and the experiences that showed us marked the way forward.

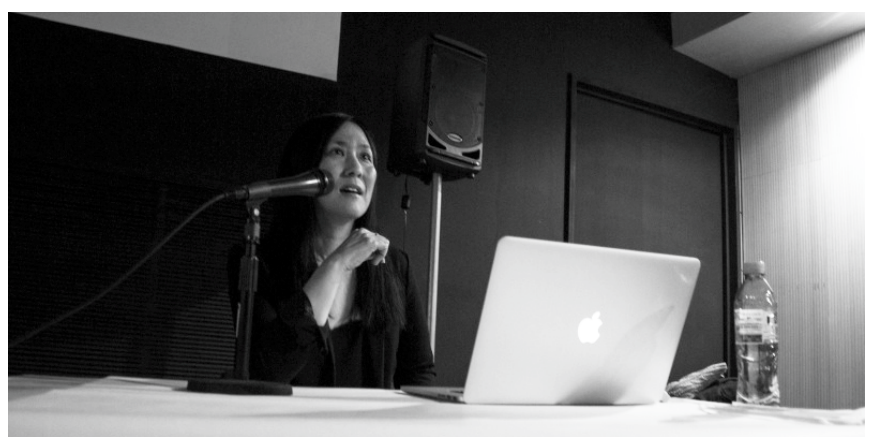

Figure 1: Lisa Iwamoto lecture in FADU-UBA 


\section{Digital Morphogenesis}

At this stage the morphogenetic exploration and the first approximation to materialization were performed. Sectioning uses a series of profiles, whose edges follow the lines of geometry of the surface. (Does not recreate the surface itself). This approach streamlines the design process, making serialized parallel sections. So we began with a collective process of Form finding in Rhino / Grasshopper in relation to the Contour tool using parallel sections in a single direction (Fig. 2), testing with different number of cuts from the boundary of the object box. From the rendering of the forms a feedback was generated and those characteristics that highlight the virtues of the sectioning strategy were chosen, in this case we worked with the continuity of surfaces of double curvature. Then the necessary perturbations or iterations were applied to find the variability that allowed the fragmentation of the form (since there existed the a priori of working with wooden rods of relatively short lengths in the object $1: 1$ ).

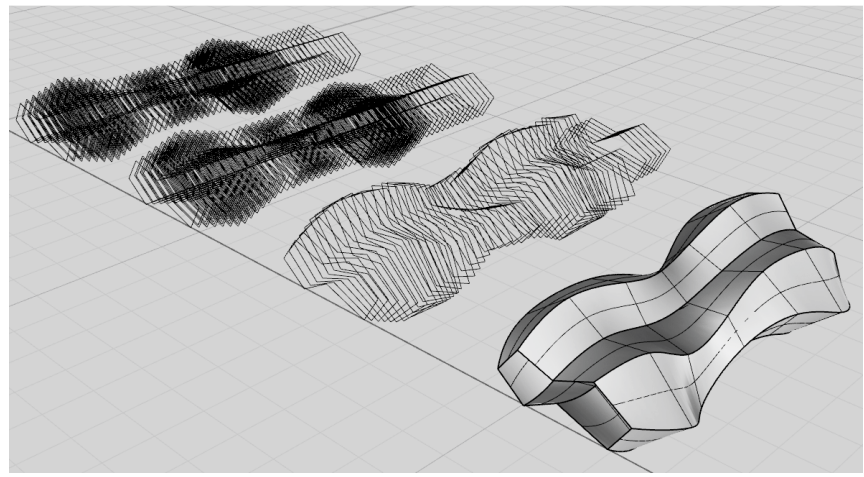

Figure 2: First digital models with the Contour operation

We worked the Grasshopper definition to approach the projected object. The curve of the section was transformed into polygonal contour by choosing the option that offered a better balance between the preservation of the characteristics of the shape and the smaller number of sides (thinking about the subsequent work of cutting and assembly of the pieces), were tested several strategies to triangulate from the vertices aimed at achieving a non-deformable structure (anticipating the selfsupporting truss to be constructed later) and the sections were given thickness to simulate the effect generated by the relation between full and empty of the final object (Fig.3).

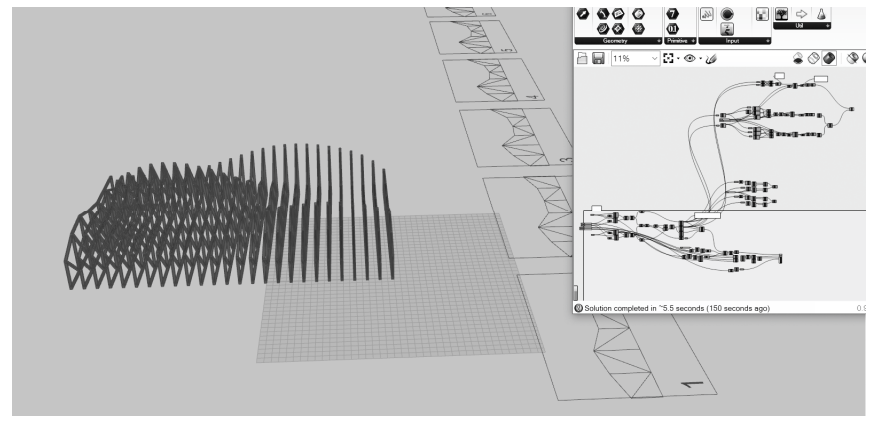

Figure 3: The model with the sections to be laser cutted.

The model was rendered to explore the best options taking advantage of the possibility of generating variants from the alteration of the parameters in Grasshopper. And scale models with laser cut were made of the best options (Fig.4). From the work with the different options we conclude that in order to enhance the effect of the continuity of the form versus the discontinuity of the material it was desirable to perceive the space between the sections, which led us to try with forms that would present more pronounced curves. On the other hand, taking into account the difference between the coplanarity of the laser cut and the actual assembly, we conclude that it would be better to exploit the "bony" or "vertebral" characteristics that come from crossing the wooden rods.

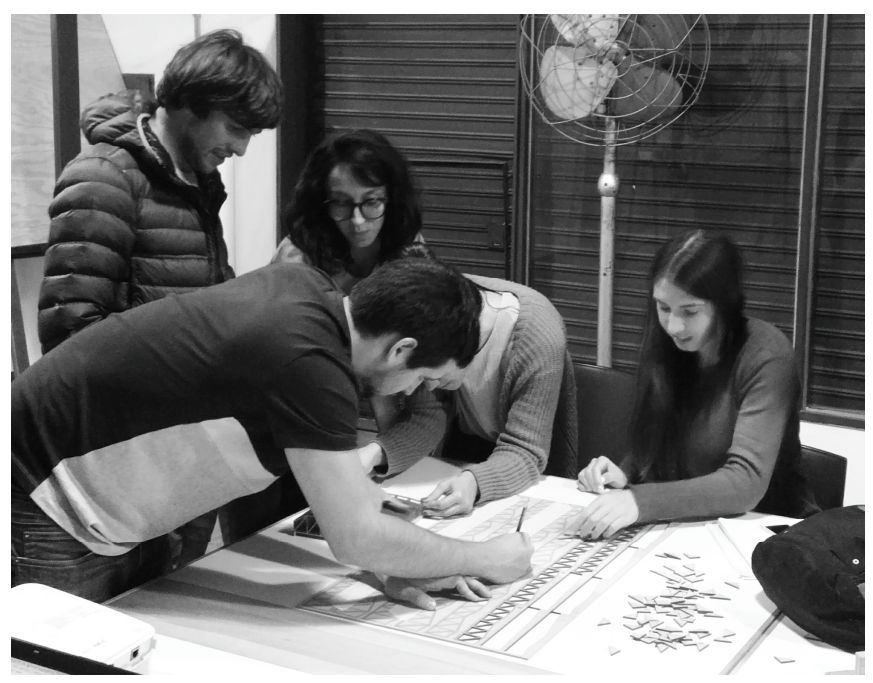

Figure 4: Scale model assembly of the laser cut sections.

In a second level of approximation to materialization small scale models of the cross-sections were made with small rods to test the overlapping modes and to solve the problems that arose from these overlaps (this because we chose to work with the idea of screwing or nailing the rods to avoid the problem of the enormous variability of the knots due to the irregularity of the angles). Tests of the various types of encounters possible on a 1:1 scale were also conducted to explore the technical problems of the encounters and to anticipate the fixation requirements. Once detected several problems related to the coplanarity of certain groups of truss rods, a possible solution was chosen using three different planes to group the rods. Then we moved to the Grasshopper definition to generate a digital model of the sections with the three planes of rods and explore their morphological possibilities from this new feature (Fig.5).

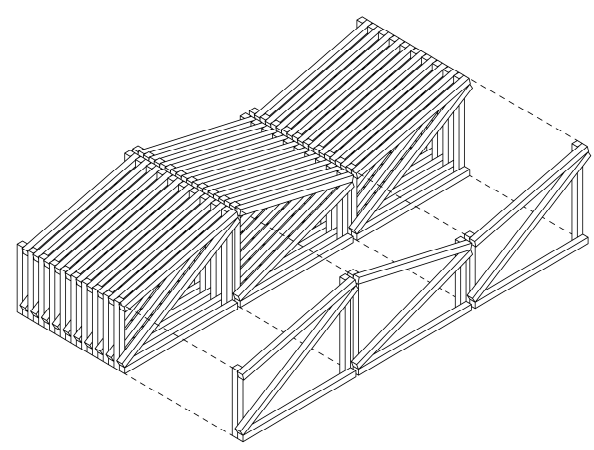

Figure 5: Model with the triplanar trusses and its effect. 


\section{Architectural Rotoscopy}

Due to the need to rationalize the use of resources, the idea of projecting the sections for assembly appears, obviously so as not to have to plot on paper. At this point, parametric design converges with traditional construction techniques from a new element that comes from cinematography, rotoscoping. This is an animation technique used by animators to track moving images, frame by frame, when realistic action is required. Originally, the images of real-life movies were projected onto a glass panel and redrawn (Fig. 6). In our case there is a coincidence between the flat sections originated in the digital model and the frame of the films used by rotoscopy.

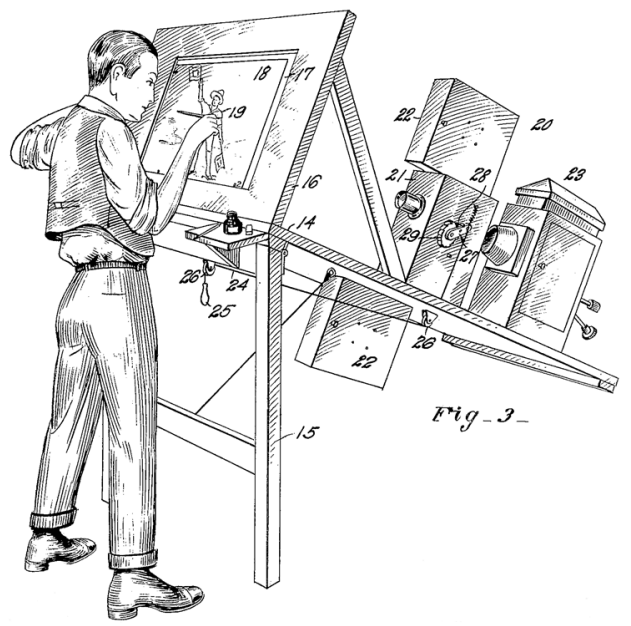

Figure 6: Patent drawing for Fleischer's original rotoscope.

Once the definitive sections were determined, a series of PDF documents were produced that would serve to make the projections. The fundamental sense was to facilitate the tasks of cutting and assembly of the pieces, for which it was necessary to generate in the documentation of the sections a code that allowed differentiating the different planes of assembly of the rods of the truss, the links and the places of union with the next truss. Several tests were then performed to determine the distance to which the projector was to be located and the operation of the system (Fig. 7). It was decided to hang the projector at a height of 5.50 meters.

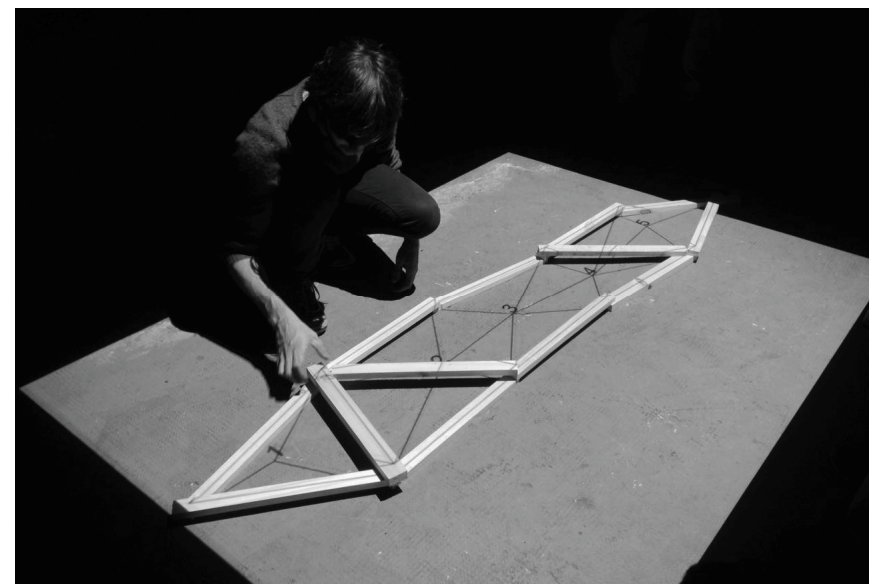

Figure 7: Testing the rotoscoping system.
Finally, in the weeks before the final workshop, the work of cleaning the wooden rods (of a square inch of section) and the cutting of the same in rods of half square inch, which was due to the speculations made in the digital model on the proper thickness. Assembly of the projection equipment and the connections with the computers were carried out in the space chosen for the workshop. All the final technical documentation was also prepared, the necessary materials were bought and logistics was organized for transportation and the availability of the tools.

\section{Hybrid Manufacturing}

The work of constructing the 1:1 scale object was carried out in an intensive two-day workshop. The group of researchers, students, interns and volunteers were separated into two teams, one dedicated to marking, cutting and assembling the rods that constituted each truss using the already explained rotoscoping technique (Fig. 8). And another dedicated to the assembly of the trusses to each other, for which threaded rods and nuts were used (Fig.9). In addition to those responsible for the photographic and audiovisual record of the process. It is important to note that the amplitude of cheLa's facilities was fundamental to the success of the process.

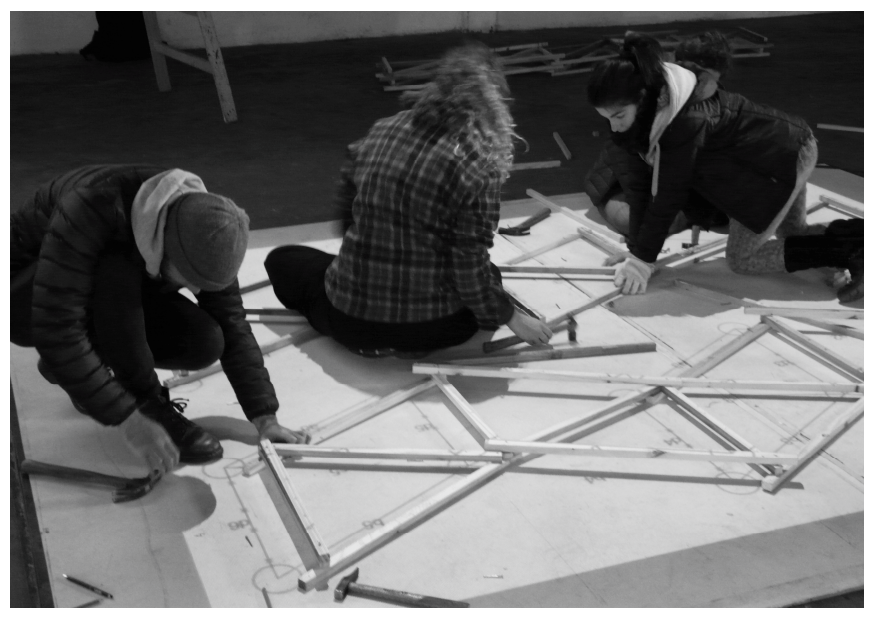

Figure 8: Assembly of the wooden rods with rotoscoping.

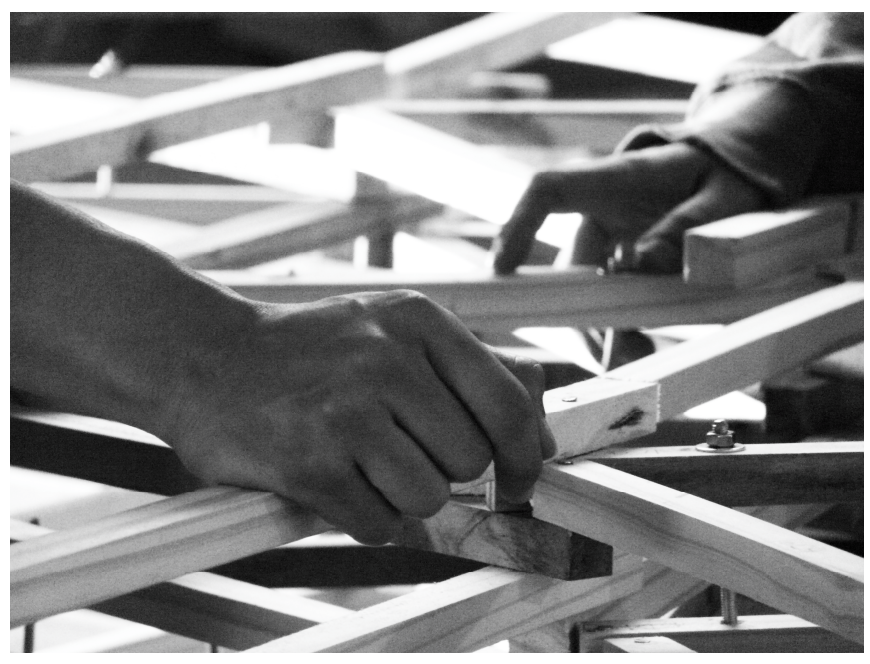

Figure 9: Hand craft assembly of the trusses. 
We are convinced that research on translation and feedback modes in digital design and manufacturing processes must include the hybridization of analogical media and craft techniques in new and original ways (McCullogh, 2000, Daru, 1998, Aish, 2005, Choma, 2010, Weston, 2013, Gokmen, 2014, Bacinoglu, 2015), but especially in the context of our developing countries. In this sense we have learned a lot from this experience.

It was possible to complete approximately two-thirds of the projected object, which evidently led us to have a more precise notion of the times involved in terms of tasks and the number of people in the work teams. Undoubtedly, the final result shows a certain loss of precision with respect to the cases of digital manufacture of complete sections, something that we could already anticipate since, even to a greater extent than in the original rotoscoping cinematographic process (Fig.10), the results can have slight deviations from the true line due to the separation of the projected image and the surface used for tracing.

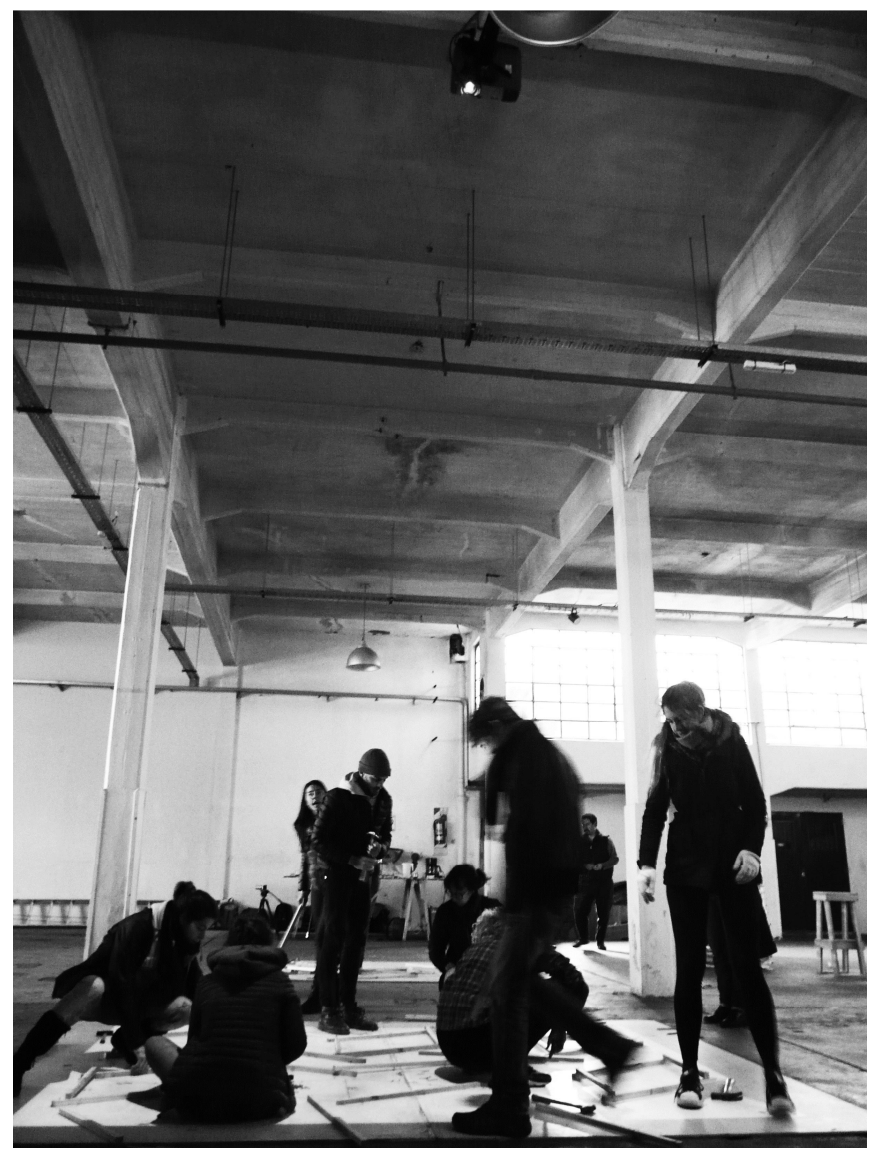

Figure 10: Operating architectural rotoscoping system.

It is possible to appreciate very interesting aesthetic, morphological, expressive and structural possibilities that arise from the strategy of using discrete elements and crosssections. In this sense we are already thinking of possible architectural and urban installations with specific uses. In addition it opens an internal research line that will work with the geometries that we have found in the parametric generation of the reticulated forms and their connections with bioinspired and biomimetic design (Fig.11).

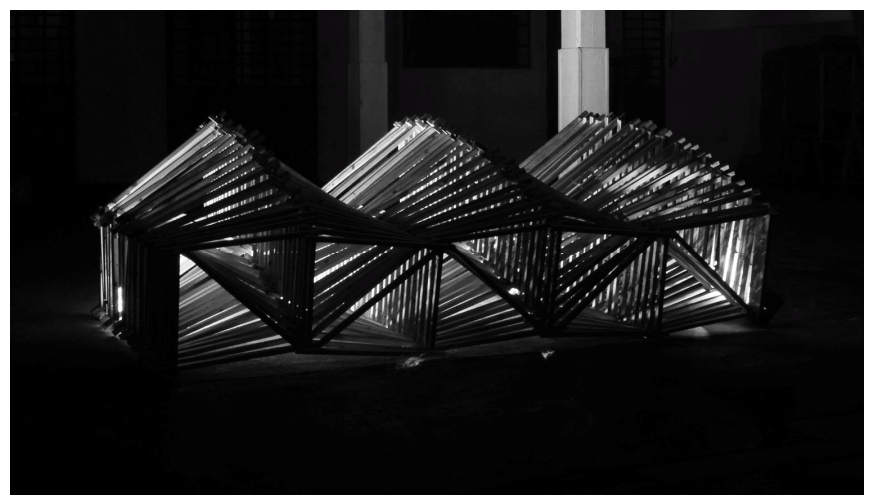

Figure 11: Finished object with backlight.

\section{Open Questions}

What are the possibilities of this type of structure? Obviously, the degree of accuracy is lower than in the cases of digital fabrication of the complete object or large pieces, as discussed above, but nevertheless this technique allowed us to explore a structural design that we consider more architectonic than those that use plate sections (in a single direction or waffle type), therefore, we consider that the possibilities that are open of application of these techniques and strategies in the architectural construction are very promising (Fig.12).

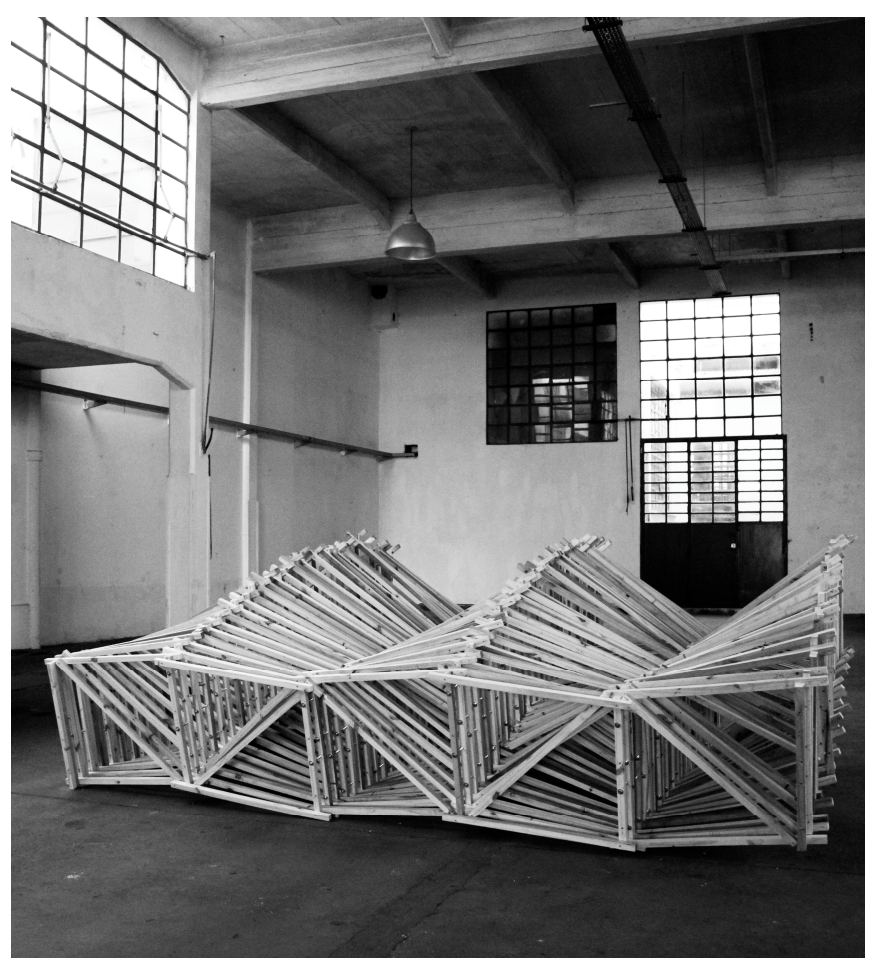

Figure 12: Finished object.

What are the possibilities of rotoscoping? It is certainly a technique with potential that requires adjustments. You have to improve the control of the projection angle, you have to use a projector with a higher resolution and you have to improve the coding. On the other hand, the results could also be improved by using a non-slip surface and a more precise technique for joints (e.g. self-tapping screws). The mismatches 
in the assembly of the trusses remain to be solved, which is where the object is most exposed to continuity errors.

Meanwhile, the process reveals a series of analogies between the cinematographic and architectural universes: the cinematographic frame and the architectural cut, the cinematographic time and the space of the guideline along which the cuts are generated, the illusion of motion in the cinema and the illusion of curvature on a sectioned architectural surface, between the fluency of an animation and the mathematical formula corresponding to the generatrix of the architectural volume.

Finally, this is just the second of four projects (workshops) planned in this research. The work of observation, archiving, analysis of results, evaluation and constructive criticism are necessary steps to approach the fundamental objective of the whole research project, to reflect and theorize on the translation processes between different technical media (focusing on virtual-physical and digital-analogical) and feedback phenomena which make complex the assumed linearity of the process.

\section{Acknowledgments}

We want to acknowledge the Fondo Nacional de Las Artes (FNA) for the funding that allow us to bring Lisa Iwamoto to Buenos Aires and the Centro Hipermediático Experimental LatinoAmericano (cheLA) for allow the use of their spaces. Also we want to acknowledge the research team, the students and interns of the FADU-UBA, the volunteers, technicians, photographers and everyone else involved in this Project for their commitment and effort.

\section{References}

Aish, Robert (2005) "From Intuition to Precision". In: Digital Design: The Quest for New Paradigms [23nd eCAADe Conference Proceedings / ISBN 0-9541183-3-2] Lisbon (Portugal) 21-24 September 2005, pp. 10-14

Bacinoglu, Saadet Zeynep (2015) "From material to material with new abilities. Performative Skin: an unfinished product derived through the organizational logic as developed through research on 'movement". In: SIGRADI 2015 [Proceedings of the 19th Conference of the Iberoamerican Society of Digital Graphics - vol. 2 - ISBN: 978-85-8039-133-6] Florianópolis, SC, Brasil 23-27 November 2015, pp. 631-636.

Batistello, Paula; Balzan, Katiane Laura; Piaia, Luana Peroza; Miotto, Juliano (2015) "Rapid prototyping and digital fabrication in vertical atelier: from process to materialization". In: SIGRADI 2015 [Proceedings of the 19th Conference of the Iberoamerican Society of Digital Graphics - vol. 1 - ISBN: 978-85-8039-135-0] Florianópolis, SC, Brasil 23-27 November 2015, pp. 137-142.

Choma, Joseph (2010) "CONTESTED BOUNDARIES: Digital Fabrication + Hand Craft". In: SIGraDi 2010 Proceedings of the 14th Congress of the Iberoamerican Society of Digital Graphics, pp. Bogotá, Colombia, November 17-19, 2010, pp. 146-149.

Daru, Roel (1998) "Architectural Bitmanship: Towards New Experiments in Architectural Education". In: Computerised Craftsmanship [eCAADe Conference Proceedings] Paris (France) 24-26 September 1998, pp. 44-60.
Frogheri, Daniela; Estévez, Alberto T. (2016) "Entre el pensar y el hacer avanzados [Between the advanced thinking and the advanced making]". In: SIGraDi 2016 [Proceedings of the 20th Conference of the Iberoamerican Society of Digital Graphics ISBN: 978-956-7051-86-1] Argentina, Buenos Aires 9 - 11 November 2016, pp.219-226

García Amen, Fernando; Martin Iglesias, Rodrigo; Schieda, Alejandro; Lagomarsino, Federico; Miret, Santiago (2016) "Digital domes that become urban symbionts", p. 892-896. In: XX Congreso de la Sociedad Iberoamericana de Gráfica Digital [=Blucher Design Proceedings, v.3 n.1]. São Paulo: Blucher, 2016. ISSN 23186968, DOI 10.5151/despro-sigradi2016-809.

Gokmen, Sabri (2014) "Tangle Jungle": An Experimental Project to Combine Collaboration and Craftsmanship in Digital Design Pedagogy". In Rethinking Comprehensive Design: Speculative Counterculture, Proceedings of the 19th International Conference on Computer-Aided Architectural Design Research in Asia (CAADRIA 2014) / Kyoto 14-16 May 2014, pp. 13-22.

Herrera, Pablo C. (2016) "Artesanía en Latinoamérica: Experiencias en el contexto de la Fabricación Digital [Artisanship in Latin America: Experiences in the context of Digital Fabrication]". In: SIGraDi 2016 [Proceedings of the 20th Conference of the Iberoamerican Society of Digital Graphics - ISBN: 978-956-705186-1] Argentina, Buenos Aires 9 - 11 November 2016, pp.426-432

Iwamoto, Lisa (2009). Digital Fabrications: Architectural and Material Techniques. New York: Princeton Architectural Press.

Martin Iglesias, Rodrigo (2014) "Reverse Design o la deconstrucción proyectual del diseño", p. 101-105 . In: Proceedings of the XVIII Conference of the Iberoamerican Society of Digital Graphics: Design in Freedom [=Blucher Design Proceedings, v.1, n.8]. São Paulo: Blucher, 2014. ISSN 2318-6968, DOI 10.5151/desprosigradi2014-0016.

McCullogh, M. (2000) Abstracting Craft: The Practised Digital Hand. MIT Press, Cambridge Mass.

Muñoz, Patricia (2016) "La transferencia y las asociaciones colaborativas [Research implementation and collaborative associations]". In: SIGraDi 2016 [Proceedings of the 20th Conference of the Iberoamerican Society of Digital Graphics ISBN: 978-956-7051-86-1] Argentina, Buenos Aires 9 - 11 November 2016, pp.347-351

Schunemann, Frederick Gorsten; Celani, Gabriela (2015) "Integration between analog and digital in Architecture". In: SIGRADI 2015 [Proceedings of the 19th Conference of the Iberoamerican Society of Digital Graphics - vol. 1 - ISBN: 978-85-8039-135-0] Florianópolis, SC, Brasil 23-27 November 2015, pp. 126-128.

Sperling, David M., Herrera, Pablo C. (2015a) Homo Faber: Digital Fabrication in Latin America, CAAD futures 2015. São Carlos. Instituto de Arquitetura e Urbanismo.

Sperling, David M.; Herrera, Pablo C.; Celani, Gabriela; Scheeren, Rodrigo (2015b) "Digital Fabrication in South America: mapping lines of action from architecture and urbanism". In: SIGRADI 2015 [Proceedings of the 19th Conference of the Iberoamerican Society of Digital Graphics - vol. 1 - ISBN: 978-85-8039-135-0] Florianópolis, SC, Brasil 23-27 November 2015, pp. 119-125.

Weston, Mark (2013) "CNC Sponge-Forming and Parametric Slip Casting: Experiments in the hybridization of computation and traditional craft for architectural ceramics". In: ACADIA 13: Adaptive Architecture [Proceedings of the 33rd Annual Conference of the Association for Computer Aided Design in Architecture (ACADIA) ISBN 978-1-926724-22-5] Cambridge 2426 October, 2013), pp. 455-456. 